\title{
Impaired Contextual Modulation of Memories in PTSD: An fMRI and Psychophysiological Study of Extinction Retention and Fear Renewal
}

\author{
Sarah N. Garfinkel, ${ }^{1,2}$ James L. Abelson, ${ }^{1}$ Anthony P. King, ${ }^{1}$ Rebecca K. Sripada, ${ }^{1,3}$ Xin Wang, ${ }^{1}$ Laura M. Gaines, ${ }^{1}$ \\ and Israel Liberzon ${ }^{1,3}$ \\ ${ }^{1}$ University of Michigan, Department of Psychiatry, Ann Arbor, Michigan 48109-2701, ${ }^{2}$ Brighton and Sussex Medical School, Department of Psychiatry, \\ Falmer BN1 9RR, United Kingdom, and ${ }^{3}$ Ann Arbor Veterans Affairs, Michigan 48105
}

Post-traumatic stress disorder (PTSD) patients display pervasive fear memories, expressed indiscriminately. Proposed mechanisms include enhanced fear learning and impaired extinction or extinction recall. Documented extinction recall deficits and failure to use safety signals could result from general failure to use contextual information, a hippocampus-dependent process. This can be probed by adding a renewal phase to standard conditioning and extinction paradigms. Human subjects with PTSD and combat controls were conditioned (skin conductance response), extinguished, and tested for extinction retention and renewal in a scanner (fMRI). Fear conditioning (light paired with shock) occurred in one context, followed by extinction in another, to create danger and safety contexts. The next day, the extinguished conditioned stimulus $(\mathrm{CS}+\mathrm{E})$ was re-presented to assess extinction recall (safety context) and fear renewal (danger context). PTSD patients showed impaired extinction recall, with increased skin conductance and heightened amygdala activity to the extinguished CS + in the safety context. However, they also showed impaired fear renewal; in the danger context, they had less skin conductance response to $\mathrm{CS}+\mathrm{E}$ and lower activity in amygdala and ventral-medial prefrontal cortex compared with combat controls. Control subjects displayed appropriate contextual modulation of memory recall, with extinction (safety) memory prevailing in the safety context, and fear memory prevailing in the danger context. PTSD patients could not use safety context to sustain suppression of extinguished fear memory, but they also less effectively used danger context to enhance fear. They did not display globally enhanced fear expression, but rather showed a globally diminished capacity to use contextual information to modulate fear expression.

Key words: amygdala; context; fear conditioning; hippocampus; imaging; memory

\section{Introduction}

Post-traumatic stress disorder (PTSD) is a common and disabling condition (Kessler et al., 2005) that is accompanied by a pervasive sense of impending danger, fearfulness, and heightened arousal (Pole, 2007), even in contexts where no actual threat is present. This sense of persistent fear could be due to enhanced fear acquisition, impaired extinction processes, or inability to modulate fear expression using contextual information. Current evidence is mixed regarding acquisition and extinction learning deficits in PTSD (Blechert et al., 2007), whereas def-

\footnotetext{
Received Oct. 1, 2013; revised July 16, 2014; accepted Aug. 11, 2014.

Author contributions: S.N.G. and I.L. designed research; S.N.G., A.P.K., R.K.S., and X.W. performed research; S.N.G., A.P.K., R.K.S., X.W., L.M.G., and I.L. analyzed data; S.N.G., J.L.A., and I.L. wrote the paper.

The research reported in this article was supported by grants from the Michigan Institute for Clinical and Health Research (U028028) to S.N.G., the National Institute of Mental Health (R24 MH075999) to I.L., from the Telemedicine and Advanced Technology Research Center (W81XWH-08-2-0208) to I.L. and A.P.K., from the University of Michigan Center for Computational Medicine and Bioinformatics Pilot Grant Program to A.P.K. We thank Nicholas Giardino who provided assistance with psychophysiological data acquisition and Mike Angstadt who provided expert assistance with fMRI data analyses.

The authors declare no competing financial interests.

Correspondence should be addressed to Dr Sarah N. Garfinkel, Clinical Science Imaging Centre, Brighton and Sussex Medical School, University of Sussex, Falmer, BN1 9RR, UK. E-mail: s.garfinkel@bsms.ac.uk.

DOI:10.1523/JNEUROSCI.4287-13.2014

Copyright $\odot 2014$ the authors $\quad 0270-6474 / 14 / 3413435-09 \$ 15.00 / 0$
}

icits in extinction recall are more consistently supported ( $\mathrm{Mi}$ lad et al., 2009). Extinction recall, however, is contextdependent, and a general deficit in contextual processing could also explain the documented extinction recall deficit in PTSD. This hypothesis can be tested by extending fear conditioning paradigms to include tests of reinstatement or renewal, as well as extinction recall.

Amygdala, ventral-medial prefrontal cortex (vmPFC), and hippocampus are all involved in fear-associated learning and contextual processing (Maren et al., 2013). PTSD patients show increased amygdala activity (Rauch et al., 2000), suggesting enhanced fear signal processing and decreased vmPFC activity (Liberzon and Martis, 2006), potentially reflecting problems in emotion regulation (Ochsner et al., 2002) or fear inhibition (Quirk et al., 2000) that could contribute to both amygdala hyperactivity and extinction recall deficits (Milad et al., 2009). Hippocampus also appears abnormal in PTSD, with evidence of reduced volume (De Bellis et al., 2002), reduced hippocampal neuronal integrity (Brown et al., 2003) and aberrant activity (St Jacques et al., 2011). Given the role of amygdala, hippocampus, and $\mathrm{mPFC}$ in context-dependent fear learning (Orsini et al., 2011), this evidence supports more extensive examination of context processing in PTSD. 

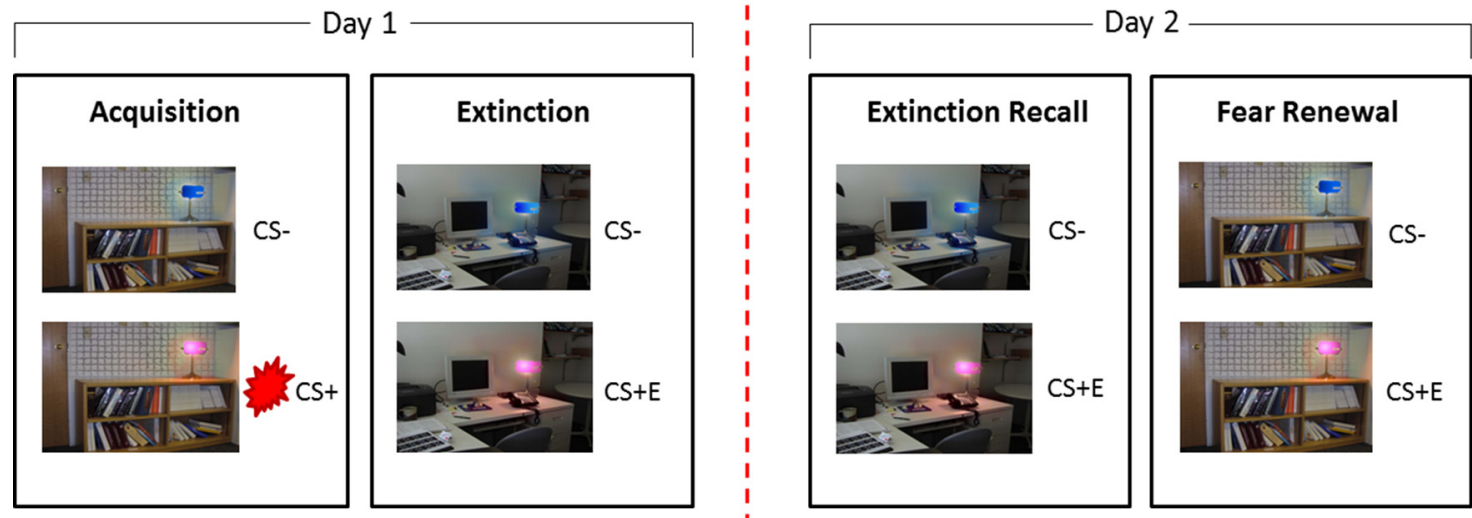

Figure 1. Fear conditioning, extinction, extinction recall and renewal. Fear conditioning contingencies were established on day 1, followed by extinction of the CS+ (to form CS +E). On day 2, extinction recall was tested using re-presentation of the extinguished $C S+$ (in the absence of shock) interleaved with CS - in the safety context. The propensity for danger context to elicit the return of fear was tested via re-presentation of the extinguished $C S+$ (again in the absence of shock) interleaved with CS - in the danger context (context that matched initial conditioned fear acquisition).

Table 1. During fear acquisition significant activation was observed to the CS+ relative to the $\mathrm{CS}$ - reflecting the fear response to the $\mathrm{CS}+$

\begin{tabular}{|c|c|c|c|c|c|}
\hline \multicolumn{6}{|c|}{ Fear conditioning: CS + vs CS - across all participants } \\
\hline Area & Side & Coordinates (mm) & $K$ (voxels) & Z-score & $p$-FWE \\
\hline Amygdala* & L & $-15,-3,-15$ & 26 & 3.56 & 0.040 \\
\hline Amygdala* & $\mathrm{R}$ & $18,0,-15$ & 12 & 3.41 & 0.063 \\
\hline Hippocampus* & L & $-12,-33,-6$ & 15 & 3.19 & 0.143 \\
\hline Hippocampus* & $\mathrm{R}$ & $9,-33,-6$ & 31 & 3.30 & 0.093 \\
\hline Insula* & L & $-45,15,-3$ & 162 & 4.33 & 0.008 \\
\hline Insula* & $\mathrm{R}$ & $36,-18,9$ & 68 & 4.44 & 0.018 \\
\hline vmPFC* & & $0,39,9$ & 8 & 3.01 & 0.367 \\
\hline Thalamus & L & $-3,-21,0$ & 774 & 5.53 & 0.001 \\
\hline Brainstem & $\mathrm{R}$ & $9,-27,-18$ & & 3.78 & \\
\hline Caudate & $\mathrm{R}$ & $15,3,9$ & & 3.76 & \\
\hline Parahippocampal gyrus & L & $-90,-12$ & 136 & 5.29 & 0.006 \\
\hline Parietal Lobe & $\mathrm{R}$ & $54,-30,21$ & 804 & 4.88 & $<0.001$ \\
\hline Rostral anterior cingulate & L & $-3,36,12$ & 123 & 4.24 & 0.010 \\
\hline Subcallosal ACC & L & $-3,27,-6$ & & 3.66 & \\
\hline Cerebellum & $\mathrm{R}$ & $-24,-57,-27$ & 168 & 3.56 & 0.002 \\
\hline
\end{tabular}

Collapsed activation is shown across groups. No significant differences in activation were obtained in PTSD relative to combat control participants. All analyses are FWE corrected $p<0.05$, bold denotes peak global maxima within a cluster.

*Indicates small volume correction (SVC).

Contextual information is critical for interpreting ambiguous cues, modulating expression of stimulus-response contingencies when cue meanings depend on specific environments (Maren et al., 2013). When fear acquisition and extinction occur in different contexts, fear returns when a conditioned stimulus (CS) is reintroduced in the acquisition context, a phenomenon known as fear renewal (Bouton et al., 2006). In contrast, when the extinguished CS is reintroduced in the extinction context, it does not elicit fear, demonstrating extinction recall. The acquisition environment thus represents a "danger" context and the extinction environment a "safety" context. It has been suggested that PTSD patients fail to use safety signals (Jovanovic et al., 2012), but if they have a general deficit in context processing, they should have difficulty identifying danger contexts as well, and might, paradoxically, show diminished rather than enhanced fear renewal (Liberzon and Sripada, 2007).
To test for a general deficit in contextual processing (reduced capacity to use safety or danger contexts to shape responses to CS re-exposure), and examine the underlying neurocircuitry in PTSD, we used a modified fMRI paradigm (Milad et al., 2005), testing both extinction recall and fear renewal. The "prevailing" memory shaping brain and behavioral responding was contingent on context, allowing assessment of whether it was modulated by context appropriately, with the counter-intuitive prediction that a general context-processing deficit would produce reduced fear expression in PTSD in the danger context.

\section{Materials and Methods}

Participants. All participants $(N=28)$ were male Operation Enduring Freedom and Operation Iraqi Freedom (OEF/OIF) veterans recruited from the Ann Arbor Veterans Affairs (VA) Outpatient Psychiatry Clinic. One-half had PTSD $(N=14)$ and one-half were combat controls $(N=$ 14). The Structured Clinical Interview for DSM-IV (First et al., 2002) was administered to establish PTSD diagnosis, and to ensure that combat control participants had not met criteria for PTSD at any point in their lives and were free of depression or any other Axis I disorder. PTSD was always the primary diagnosis in PTSD subjects, but seven of them also met diagnostic criteria for comorbid depression, and one had comorbid panic disorder. No psychiatric medications were permitted with the exception of low-dose trazodone as a sleep aid, used by two PTSD participants. No subject had history of traumatic brain injury, or chronic medical or neurological illness. Those with prior substance abuse/dependence histories had to be in remission ( $>6$ months) to be eligible. Groups were matched on key demographic variables including marital status $\left(\chi^{2}\right.$ $=6.27, p=0.10)$, level of education $\left(\chi^{2}=5.39, p=0.15\right)$, age $(t=0.477$, $p=0.64)$, and race $\left(\chi^{2}=4.18, p=0.52\right)$. After full explanation of study procedures, written informed consent was provided in accordance with the specifications of the IRBs of the University of Michigan Medical School and the Ann Arbor VA Healthcare System.

Design overview. The experiment was run over $2 \mathrm{~d}$; with fear conditioning in a danger context, followed by subsequent fear extinction in a "safe" context on day 1 , and tests of extinction memory recall and fear renewal on day 2. Participants were fear conditioned in a modified version of the Milad et al. (2007) paradigm using two contexts (library and office). Within a randomly assigned danger context, lamps turning pink and blue depicted the CS + and CS- (Fig. 1). A 500 ms shock delivered to the index and middle fingers was the unconditioned stimulus (US), titrated in strength on an individual basis to be subjectively defined as "highly annoying 
Fear Acquisition

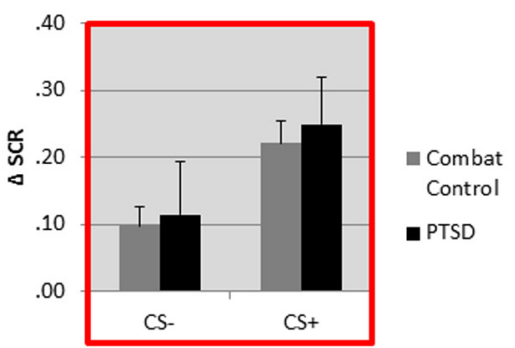

Extinction Recall

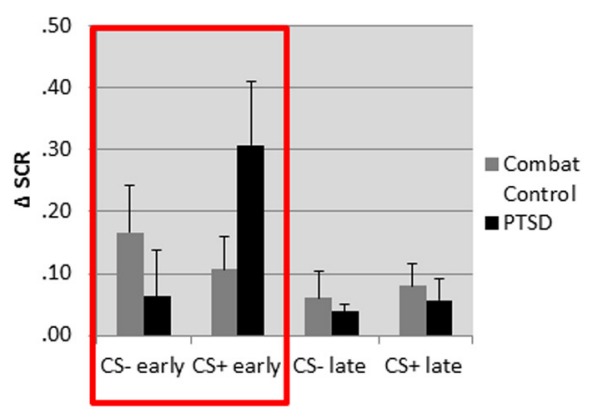

Fear Extinction

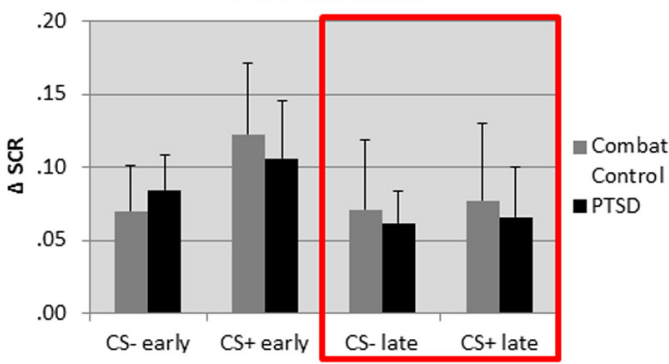

Fear Renewal

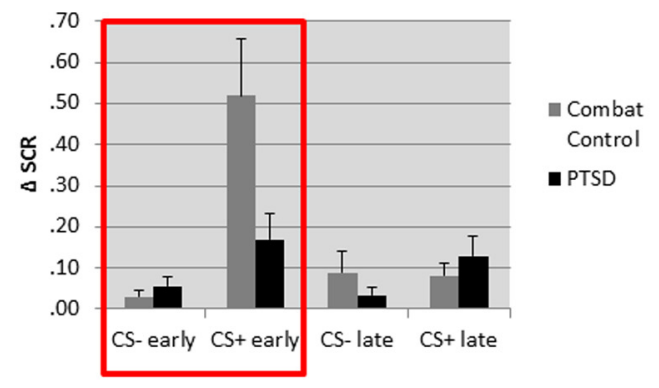

Figure 2. Graphs depicting SCR responses in all experimental phases, with day 1 divided into fear acquisition and early and late extinction. Day 2 was comprised of early and late extinction recall in the safety context, followed by early and late fear renewal in the danger context. These data demonstrate that fear acquisition learning and extinction learning were intact for PTSD patients during day 1 . However, PTSD patients exhibited a failure to effectively recall the extinction memory in the safety context and were also unable to effectively renew the fear memory in the danger context. Both of these effects on day 2 occurred during the early phases, before effective extinction learning again prevailed. The red boxes highlight the experimental phases of greatest interest, which were taken forward to fMRI analyses.
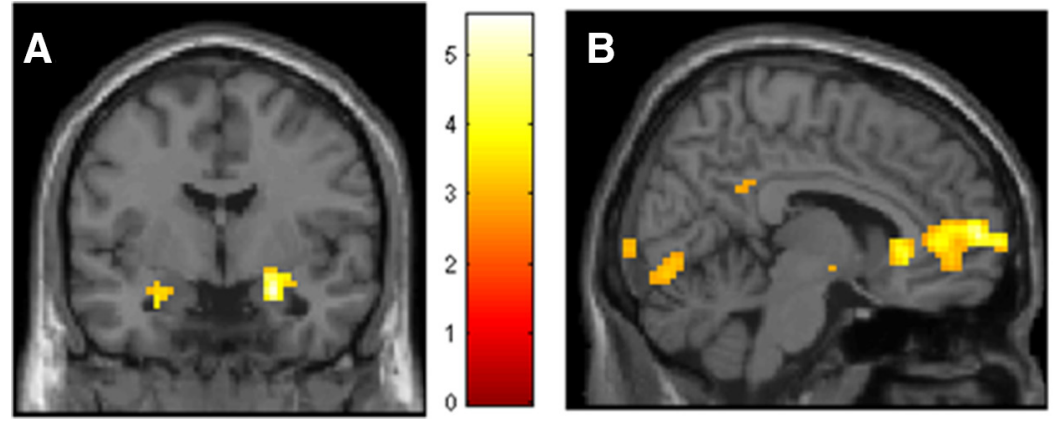

Figure 3. ROI presentation of enhanced bilateral activity in the amygdala in PTSD patients during extinction recall (CS + verses $(S-)(A)$. Contrast of $C S+E$ during extinction recall, greater in combat controls relative to PTSD patients, demonstrating enhanced recruitment of vmPFC in combat controls $(\boldsymbol{B})$.

but not painful" (Orr et al., 2000). Extinction occurred within the safety context immediately following acquisition, with CS presentation alone (no US, creating the $\mathrm{CS}+\mathrm{E}$ trace). On day 2, context effects were tested in two ways. For extinction recall, the unreinforced CS was again presented in the safety (extinction) context. For renewal, the unreinforced CS was presented in the danger context (where original fear acquisition took place). To assess conditioned response to the CSs, we measured skin conductance response (SCR) peripherally, and BOLD signal changes centrally, to CS + (or CS +E in the case of extinction recall and renewal) compared with CS-.

Procedures. Habituation, fear acquisition, and immediate fear extinction occurred on day 1 within the scanner in three separate functional runs. Habituation involved 12 presentations of context-light pairings to insure that participants were familiar with stimuli and contexts. During acquisition, one context (office or library, counterbalanced betweensubjects) was presented for 2-7 s, followed by CS (a pink or blue light) for an additional $2-7 \mathrm{~s}$, with each epoch controlled to last $9 \mathrm{~s}$ in total. For the $\mathrm{CS}+$, the US was delivered at $60 \%$ contingency ( 5 of 8 trials), to coincide with CS offset. The other CS was presented 16 times, and was never associated with shock (forming the CS - ). The 16 CS - trials were inter-

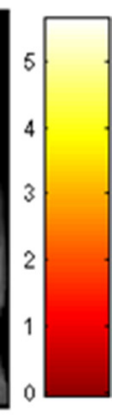

leaved with $16 \mathrm{CS}+$ trials (see below). The intertrial interval (ITI) was a white fixation cross on a black background, jittered for 12-18 s. Extinction followed immediately, with a switch in context (from office to library or vice versa) and 16 presentations of the CS + in the absence of the US, interleaved with 16 CS - presentations. On day 2, participants returned to undergo extinction recall and fear renewal testing in the fMRI scanner. For extinction recall, testing was done in the safety context. Participants were again shown the CS- (16 presentations) interleaved with the extinguished CS+E $(8$ presentations). For fear renewal, the context was changed to the danger context (used during fear acquisition), with identical presentations of CS - and CS+ (no shock). Stimulus and ITI timings were identical on days 1 and 2. A second CS+ (yellow light) was presented 8 times during all three phases: acquisition (followed by shock on 5 of 8 trials), extinction recall, and renewal. This ensured that ratios of CS + to CS - were equal in all experimental phases. This additional design feature was intended for separate analyses and is not included in the present report, beyond its role in balancing $\mathrm{CS}+$ and CS - presentations.

Psychophysiological measures. Psychophysiological data were analyzed using established procedures (Pitman and Orr, 1986; Orr et al., 2000; Milad et al., 2005). Biopac AcqKnowledge software was used to acquire the SCR trace within the fMRI environment and to calculate SCR scores using event related electrodermal response (EDR) analysis. The baseline estimation window was set at $2 \mathrm{~s}$ before the CS onset, adjusting corresponding EDR for baseline levels and response to context alone. EDR/SCR amplitude (uMho) was defined as the difference in skin conductance level between peak and trough values of the skin conductance trace, accounting for baseline. SCR responses to CS were defined within a $2-5 \mathrm{~s}$ window following CS presentation. First interval responses to the context alone (a minimum of $4 \mathrm{~s}$ before CS onset, or longer depending on ITI jitter intervals) were not calculated, thus restricting SCR analyses to the conditioned stimuli. Dur- 
Table 2. Brain activation pertaining to extinction recall in all subjects and broken down separately in PTSD patients and combat controls (CS + vs CS - in each case)

\begin{tabular}{|c|c|c|c|c|c|}
\hline Area & Side & Coordinates (mm) & $K$ (voxels) & Z-score & $p$-FWE \\
\hline \multicolumn{6}{|l|}{$\begin{array}{l}\text { Extinction recall: } \mathrm{CS}+\mathrm{E} \text { vs } \mathrm{CS}-\text { across all } \\
\text { participants }\end{array}$} \\
\hline Amygdala* & L & $24,-15,-6$ & 4 & 2.83 & 0.142 \\
\hline Amygdala* & $\mathrm{R}$ & $-30,-6,-15$ & 29 & 3.20 & 0.043 \\
\hline Hippocampus* & $\mathrm{L}$ & $-12,-33,-9$ & 41 & 3.42 & 0.129 \\
\hline Hippocampus* & $\mathrm{R}$ & $21,-33,0$ & 11 & 3.27 & 0.253 \\
\hline Insula* & $\mathrm{L}$ & $-33,15,-12$ & 125 & 4.30 & 0.006 \\
\hline Insula* & $\mathrm{R}$ & $33,18,-15$ & 94 & 3.71 & 0.013 \\
\hline vmPFC & & $-3,45,12$ & 65 & 3.26 & 0.065 \\
\hline Medial frontal gyrus & $\mathrm{R}$ & $3,42,36$ & 226 & 4.65 & $<0.001$ \\
\hline Anterior cingulate & $\mathrm{R}$ & $15,33,18$ & & 3.89 & \\
\hline Inferior frontal gyrus/anterior Insula & L & $-33,-84,-27$ & 59 & 4.50 & 0.05 \\
\hline Lingual gyrus/occipital lobe & L & $-6,-87,-3$ & 273 & 4.18 & $<0.001$ \\
\hline Inferior frontal gyrus & $\mathrm{R}$ & $57,21,6$ & 59 & 4.16 & 0.05 \\
\hline Caudate & $\mathrm{R}$ & $24,18,18$ & 62 & 4.12 & 0.044 \\
\hline Claustrum/putamen & R & $33,3,3$ & 68 & 4.08 & 0.032 \\
\hline Inferior frontal gyrus/anterior insula & R & $33,18,-15$ & & 3.90 & \\
\hline Superior temporal gyrus & L & $-51,0,3$ & 63 & 3.97 & 0.042 \\
\hline Brainstem & R & $9,-30,-15$ & 63 & 3.78 & 0.042 \\
\hline Caudate & $\mathrm{R}$ & $9,3,9$ & 75 & 3.74 & 0.022 \\
\hline \multicolumn{6}{|l|}{$\begin{array}{l}\text { Extinction recall: CS + Evs CS - in PTSD } \\
\text { patients only }\end{array}$} \\
\hline Amygdala* & L & $-36,-12,-21$ & 36 & 3.20 & 0.028 \\
\hline Amygdala* & $\mathrm{R}$ & $24,0,-18$ & 49 & 3.84 & 0.018 \\
\hline Hippocampus* & $\mathrm{L}$ & $-12,-33,-9$ & 29 & 3.52 & 0.108 \\
\hline Hippocampus* & R & $15,-36,9$ & 84 & 3.90 & 0.017 \\
\hline Insula* & L & $-36,-12,-3$ & 313 & 4.08 & $<0.001$ \\
\hline Insula* & $\mathrm{R}$ & $33,-18,-3$ & 296 & 4.49 & $<0.001$ \\
\hline $\operatorname{vmPFC}{ }^{*}$ & & $-9,45,6$ & 169 & 4.52 & 0.003 \\
\hline Occipital lobe & $\mathrm{R}$ & $18,-72,-12$ & 2753 & 5.12 & $<0.001$ \\
\hline Thalamus & R & $12,-3,12$ & & 4.69 & \\
\hline Putamen & $\mathrm{R}$ & $33,3,-3$ & & 4.66 & \\
\hline Prefrontal cortex & $\mathrm{R}$ & $0,36,39$ & 687 & 4.76 & 0.001 \\
\hline $\mathrm{mPFC} / \mathrm{ACC}$ & $\mathrm{L}$ & $-9,45,6$ & & 4.51 & \\
\hline Middle cingulate cortex & $\mathrm{R}$ & $3,15,42$ & & 4.17 & \\
\hline Precentral and postcentral gyrus & $\mathrm{R}$ & $42,-21,39$ & 267 & 4.54 & 0.001 \\
\hline Superior parietal & R & $63,-33,39$ & & 4.30 & \\
\hline Parietal lobe & L & $-63,-39,36$ & 395 & 4.52 & 0.001 \\
\hline Precentral gyrus & $\mathrm{R}$ & $36,-9,60$ & & 3.55 & \\
\hline Temporal lobe/superior temporal gyrus & $\mathrm{L}$ & $-51,0,3$ & 195 & 3.92 & 0.001 \\
\hline IFG & L & $-45,27,-15$ & & 3.86 & \\
\hline \multicolumn{6}{|l|}{$\begin{array}{l}\text { Extinction recall: } \mathrm{CS}+\mathrm{E} \text { vs } \mathrm{CS} \text { - in combat } \\
\text { controls only }\end{array}$} \\
\hline Amygdala* & $\mathrm{L}$ & & 0 & & \\
\hline Amygdala* & $\mathrm{R}$ & & 0 & & \\
\hline Hippocampus* & L & & 0 & & \\
\hline Hippocampus* & R & & 0 & & \\
\hline Insula* & L & $-45,9,9$ & 4 & 3.28 & 0.271 \\
\hline Insula* & $\mathrm{R}$ & $30,-18,21$ & 3 & 3.09 & 0.277 \\
\hline vmPFC & & $-3,42,9$ & 30 & 3.11 & 0.182 \\
\hline Middle frontal gyrus & L & $-54,9,48$ & 131 & 4.20 & 0.029 \\
\hline $\mathrm{mPFC}$ & & $0,54,12$ & 145 & 3.79 & 0.018 \\
\hline $\mathrm{ACC}$ & L & $-9,27,33$ & 233 & 3.52 & 0.001 \\
\hline $\mathrm{ACC}$ & R & $6,24,30$ & & 3.14 & \\
\hline
\end{tabular}

The reverse contrast of CS - versus $C$ + was not significant, either collapsed across subjects or performed separately in PTSD patients and combat controls. All activation FWE $p<0.05$, bold denotes peak global maxima within a cluster. *Indicates SVC.

ing fear acquisition, all trials that incorporated a shock were omitted from analyses to ensure SCR response to the CS was not contaminated by response to shock. To avoid skewing data due to spiking, data-points greater than $3 \mathrm{SDs}$ from the mean were omitted from analyses. Due to technical difficulties, SCR data were lost for three PTSD and three combat control subjects during measurement in the scanner on day 1 , and for two PTSD and two combat control participants on day 2; and one combat control had a corrupted data point during extinction recall that had to be removed from this analysis. To ascertain whether extinction was effective in both groups, extinction analyses focused on the latter half (50\%) of extinction trials only, a period classified as "late" extinction. Extinction recall was assessed, however, using the first half of extinction recall trials, to avoid potential "contamination" by new extinction learning (Milad et al., 2007). For the same reason and to be consistent, fear renewal analyses also focused on the first $50 \%$ of trials. This ensured that renewal analyses were not contaminated by later learning that the context was now safe. 
Table 3. Effects of group during extinction recall

\begin{tabular}{|c|c|c|c|c|c|}
\hline Area & Side & Coordinates (mm) & $K$ (voxels) & Z-score & $p$-FWE \\
\hline \multirow{2}{*}{\multicolumn{6}{|c|}{$\begin{array}{l}\text { Extinction recall: } C S+E \text { vs } C S \text { - greater in } \\
\text { PTSD patients relative to combat controls }\end{array}$}} \\
\hline $\begin{array}{l}\text { PTSD patients relative to combat controls } \\
\text { Amygdala* }\end{array}$ & & & & & 0.127 \\
\hline Hippocampus* & L & $-24,-36,6$ & 1 & 2.61 & 0.318 \\
\hline Hippocampus* & $\mathrm{R}$ & $15,-36,-9$ & 3 & 2.81 & 0.281 \\
\hline Insula* & L & $-33,18,-3$ & 28 & 3.31 & 0.089 \\
\hline Postcentral gyrus (primary somatosensory cortex) & $\mathrm{R}$ & $51,-18,33$ & 727 & 4.09 & 0.001 \\
\hline Parietal lobe & $\mathrm{R}$ & $45,-21,39$ & & 3.82 & \\
\hline Parietal lobe & $\mathrm{L}$ & $-48,-33,36$ & 236 & 3.81 & 0.018 \\
\hline Dorsal anterior cingulate cortex/midcingulate & L & $-3,18,30$ & 280 & 3.68 & 0.008 \\
\hline Putamen/pallidum & $\mathrm{R}$ & $18,6,3$ & & 3.65 & \\
\hline Caudate & $\mathrm{R}$ & $9,3,15$ & & 3.43 & \\
\hline Hippocampus* & L & & 0 & & \\
\hline Hippocampus* & $\mathrm{R}$ & $33,-12,-36$ & 10 & 3.61 & 0.178 \\
\hline Insula* & $\mathrm{L}$ & & 0 & & \\
\hline Insula* & R & $48,-6,-6$ & 5 & 3.00 & 0.213 \\
\hline vmPFC* & & $3,57,3$ & 94 & 3.40 & 0.048 \\
\hline $\mathrm{mPFC}$ & $\mathrm{R}$ & $6,60,6$ & 622 & 4.48 & $<0.001$ \\
\hline Lingual gyrus & $\mathrm{R}$ & $3,-78,-12$ & 403 & 3.66 & 0.001 \\
\hline \multicolumn{6}{|l|}{ Extinction recall: $\mathrm{CS}+\mathrm{E}$ greater in } \\
\hline \multicolumn{6}{|l|}{ PTSD relative to combat controls } \\
\hline Amygdala* & L & $-24,-12,-6$ & 1 & 2.81 & 0.127 \\
\hline Amygdala* & $\mathrm{R}$ & $27,0,-27$ & 5 & 2.77 & 0.096 \\
\hline Hippocampus* & L & & 0 & & \\
\hline
\end{tabular}

Response to $C S+E$ is also compared between groups, demonstrating enhanced vmPFC activity in combat controls relative to the PTSD patients. No significant group effects existed for CS - alone. All activation FWE $p<0.05$, bold denotes peak global maxima within a cluster.

*Indicates SVC.

fMRI acquisition and preprocessing. MRI scanning was performed on a 3.0 T GE Signa System (LX, 8.3) using a standard radio frequency 8-channel head coil. Participants underwent structural and fMRI scanning that included resting-state procedures and emotion regulation and conditioning tasks. Reports on emotion regulation tasks are forthcoming; reports of resting-state functional connectivity were previously published (Sripada et al., 2012a,b). A T1-weighted structural image was acquired with a $3 \mathrm{D}$ volume inversion recovery fast spoiled gradient recalled echo protocol $\left(\mathrm{TR}=12.3 \mathrm{~ms}, \mathrm{TE}=5.2 \mathrm{~ms}, \mathrm{FA}=9^{\circ}, \mathrm{TI}=650 \mathrm{~ms}\right.$, $\mathrm{FOV}=26 \mathrm{~cm}$, matrix $=256 \times 256$ for in-plane resolution of $1 \mathrm{~mm}$; slice thickness $=1 \mathrm{~mm}$ with no gap, 160 contiguous axial slices to cover the whole brain). This was used for landmark identification to position subsequent scans. Following acquisition of T1 structural images, functional images were acquired with a $2^{\star}$-weighted, reverse spiral acquisition sequence $(\mathrm{GRE}, \mathrm{TR}=2000, \mathrm{TE}=30, \mathrm{FA}=90, \mathrm{FOV}=220,40 \mathrm{sl}, 3.0 / 0$, matrix diameter 71, equivalent to $64 \times 64)$. Each run began with four "dummy" volumes that were subsequently discarded to allow for T1 equilibration effects. Preprocessing used the Statistical Parametric Mapping SPM8 package (Wellcome Institute of Cognitive Neurology, London, UK). Data were slice-time and motion corrected, spatially normalized to the MNI template, and smoothed using a $5 \mathrm{~mm}^{3}$ fullwidth at half-maximum Gaussian kernel.

fMRI analyses. All first and second level analyses were performed in SPM8. fMRI comparisons of interest were implemented as linear con- trasts. Six realignment parameters were added as covariates of no interest at the first level. Fixation cross, context, and cue were all modeled as separate regressors at the first level for all experimental phases (fear acquisition, fear extinction, extinction recall, and fear renewal) with both onset and duration of all factors entered into the model. For fear extinction, extinction recall and fear renewal, "early" and late, regressors were modeled separately. Echoing procedures used for the SCR analyses, to determine whether similar levels of extinction had been reached in both groups, extinction analyses focused on late extinction only (latter $50 \%$ of extinction trials). Again mirroring SCR analyses, extinction recall and renewal were assessed using the first half of extinction recall trials, to avoid potential contamination by new extinction learning (Milad et al., 2007). During fear acquisition, CS + s followed by shock were modeled separately from $\mathrm{CS}+$ in the absence of shock, allowing analyses pertaining to CS + to be analyzed uncontaminated by shock. Analyses focused on the cue alone: $\mathrm{Z}$-score images from individual analyses were entered into second-level random-effects analyses. The SPM default of one-sided $t$ tests was used in accordance with our specific predictions of enhanced fear processing in the safety context for PTSD patients and enhanced fear renewal in the danger context in combat control participants. To investigate differences to $\mathrm{CS}+/ \mathrm{CS}+\mathrm{E}$ relative to $\mathrm{CS}-$, task activation was compared within-subjects at different stages (i.e., fear acquisition, extinction, recall, renewal) using one-sample $t$ tests, and then compared in PTSD patients relative to combat controls using two- 
Table 4. Brain activity pertaining to fear renewal in combat control subjects

\begin{tabular}{|c|c|c|c|c|c|}
\hline$\overline{\text { Area }}$ & Side & Coordinates (mm) & $K$ (voxels) & Z-score & $p$-FWE \\
\hline \multicolumn{6}{|l|}{$\begin{array}{l}\text { Fear renewal: } C S+E \text { vs } C S-\text { in } \\
\text { combat control participants }\end{array}$} \\
\hline Amygdala* & L & & 0 & & \\
\hline Hippocampus* & $\mathrm{L}$ & & 0 & & \\
\hline Hippocampus* & $\mathrm{R}$ & & 0 & & \\
\hline Insula* & L & $-39,12,-3$ & 229 & 4.09 & 0.003 \\
\hline Parietal lobe & L & $-63,-54,27$ & 183 & 4.17 & 0.033 \\
\hline Parietal lobe & $\mathrm{R}$ & $63,-51,27$ & 197 & 3.67 & 0.023 \\
\hline \multicolumn{6}{|c|}{$\begin{array}{l}\text { Fear renewal: response to renewed CS+ } \\
\text { in combat controls relative to } \\
\text { PTSD patients }\end{array}$} \\
\hline Amygdala* & L & $-21,-6,-25$ & 29 & 3.56 & 0.038 \\
\hline Insula* & $\mathrm{R}$ & & 0 & & \\
\hline vmPFC* & $\mathrm{R}$ & $-9,51,-15$ & 26 & 3.48 & 0.017 \\
\hline Parietal lobe/precuneus & & $0,-60,45$ & 394 & 3.71 & 0.022 \\
\hline Occipital lobe/cuneus & R & $6,-84,33$ & & 3.63 & \\
\hline \multicolumn{6}{|c|}{$\begin{array}{c}\text { Fear renewal: response to } C S \text { - in combat } \\
\text { controls relative to PTSD patients }\end{array}$} \\
\hline Amygdala* & L & & 0 & & \\
\hline Amygdala* & & & 0 & & \\
\hline Hippocampus* & $\mathrm{L}$ & $-24,-24,-9$ & 57 & 3.60 & 0.013 \\
\hline Hippocampus* & $\mathrm{R}$ & $24,-18,-27$ & 24 & 2.87 & 0.170 \\
\hline Insula* & L & & 0 & & \\
\hline Insula* & $\mathrm{R}$ & & 0 & & \\
\hline
\end{tabular}

No effects of renewal (CS + vs CS - ) were found in PTSD patients, or when analyzing across all participants. Combat controls displayed enhanced activity in the vmPFC and amygdala to the CS + and hippocampal activation to the CS relative to PTSD patients. In contrast, PTSD patients did not display any significant activation to $C S+$ or $C S-$ relative to Combat Controls, signaling a reduced capacity for context to induce a renewal response. All activation FWE $p<0.05$ bold denotes peak global maxima within a cluster.

*Indicates SVC.

sample $t$ tests. Additional analyses investigating group differences separately for CS+ and CS - responses were also performed. For fear acquisition, the contrast of CS + versus $\mathrm{CS}$ - included only the $\mathrm{CS}+\mathrm{s}$ that were not accompanied by shock, to ensure that the data were not contaminated by response to the shock itself. Statistical threshold was set to $p$-FWE $<0.05$ corrected at cluster level (cluster size was defined using an initial voxel-level threshold $p<0.005$ uncorrected). Anatomically defined region-of-interest (ROI) analyses focused on amygdala, hippocampus, and insula. The anatomical toolbox implemented in SPM defined bilateral ROIs of amygdala ( $r=175$ voxels, $l=164$ voxels) and hippocampus ( $r=614$ voxels, $1=570$ voxels). Insula was computed with an anatomical mask created in XJVIEW (http://www.alivelearn.net/xjview) using the AAL atlas ( $r=787$ voxels, $1=860$ voxels). For vmPFC, a functional ROI was defined based on the coordinates from prior work on extinction retention ( $-10,43$, -11 ; Milad et al., 2007; Milad et al., 2009) using a $25 \mathrm{~mm}$ sphere. Mirroring whole brain analyses, all ROI analyses were $p$-FWE $<0.05$ corrected at cluster level (with clusters created by an initial threshold of $p<0.005$ uncorrected).

To assess whether key results were driven by comorbidities, subanalyses were performed including only PTSD patients without any comorbid disorders (PTSD "only" group, $N=7$ ) relative to combat controls.

\section{Results}

\section{Fear acquistion}

Across both groups, all participants successfully fear conditioned, as reflected by significantly larger SCR to the CS + relative to CS-
$\left(F_{(1,20)}=8.88, p=0.007\right)$. Fear acquisition did not differ between combat control and PTSD patients; there was no main effect of group $\left(F_{(1,20)}=0.094, p=0.76\right)$, and no group by stimulus interaction $\left(F_{(1,20)}=0.015, p=0.90\right)$. Brain effects paralleled the SCR findings, with evidence of conditioning but no PTSD versus combat control differences. BOLD signal was increased to CS+ compared with $\mathrm{CS}-$ in key areas implicated in fear learning, including amygdala, brainstem, insula, and ACC (Table 1), but brain activation during fear acquisition did not differ between PTSD and combat control patients (no significant activations at $p<0.001,10$ contiguous voxels).

\section{Extinction}

Successful extinction learning was evident peripherally and in the brain. Significant SCR differences between CS +E and CS - had disappeared by the end of extinction phase $\left(F_{(1,20)}=0.12, p=\right.$ $0.73)$ and were absent for both PTSD $\left(t_{(10)}=-0.14, p=0.891\right)$ and combat controls $\left(t_{(10)}=-0.56, p=0.590\right)$. In the brain, the contrast of $\mathrm{CS}+\mathrm{E}$ versus $\mathrm{CS}-$ for all participants during late extinction yielded no significant voxels. Extinction was also similar between PTSD patients and combat control, peripherally and in the brain. The SCR results did not demonstrate a main effect of group $\left(F_{(1,20)}=0.03, p=0.87\right)$ or a group by stimulus interaction $\left(F_{(1,20)}=0.004, p=0.951\right)$. The fMRI contrast of CS $+\mathrm{E}$ versus 

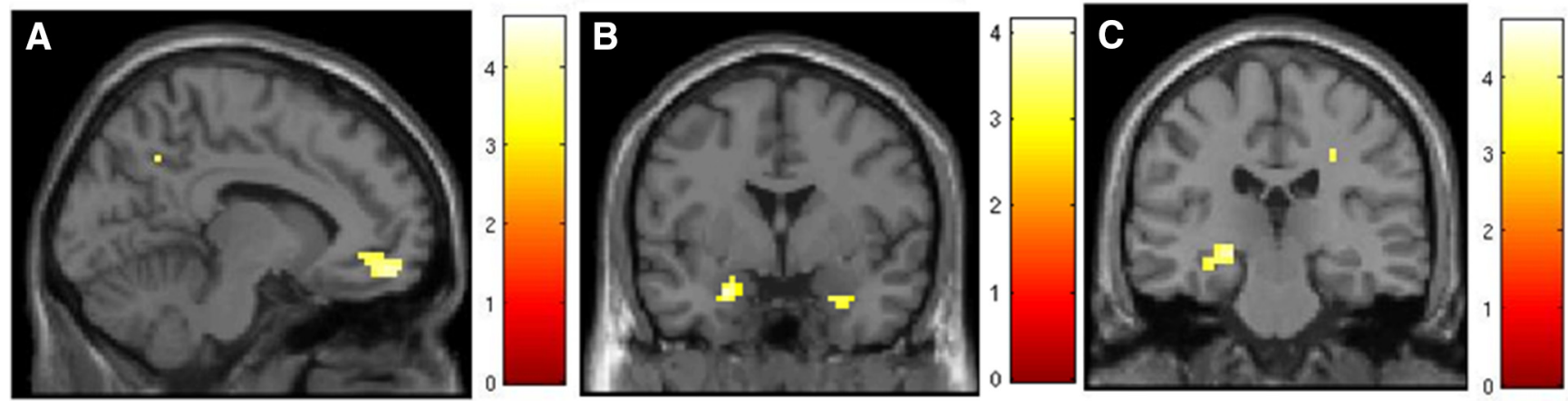

Figure 4. During fear renewal in the danger context, combat controls had enhanced activity to the $C S+$ in the vmPFC (A) and amygdala (B), and heightened hippocampal activation to the CS - ( $\boldsymbol{C}$.

CS - examining PTSD relative to combat control in late extinction yielded no significant voxels.

\section{Extinction recall}

When the CS+ was re-presented $24 \mathrm{~h}$ after extinction in the extinction (safety) context, there was no main effect of stimulus (i.e., no overall difference between CS+E vs CS -$)\left(F_{(1,21)}=\right.$ $2.354, p=0.14)$. However, the group by stimulus interaction $\left(F_{(1,21)}=6.38, p=0.021\right.$; visible in early extinction recall portion of Fig. 2) showed that differential response to the CS+E and CSwas influenced by group. Specifically, SCR was elevated to the $\mathrm{CS}+\mathrm{E}$ relative to the $\mathrm{CS}-$ for PTSD patients signaling a return of fear response to the previously extinguished CS $+\left(t_{(11)} 2.80, p=\right.$ 0.021 ), whereas for combat control subjects, these responses did not differ $\left(t_{(10)}=-0.719, p=0.491\right)$.

Mirroring analysis of the SCR, fMRI data revealed that PTSD patients had significantly enhanced activation to CS+E relative to CS- in a number of regions implicated in fear expression, sensory processing and attention, including amygdala, insula, thalamus, occipital lobe, and parietal cortex (Fig. 3a; Table 2), whereas combat control participants did not display any significant activation to the CS + relative to the $\mathrm{CS}-$. In response to the $\mathrm{CS}+\mathrm{E}$ and relative to the PTSD group, combat control participants activated a large cluster within the vmPFC (previously implicated in extinction recall deficits in PTSD patients; Milad et al., 2009). This analysis showed reduced $\mathrm{mPFC} / \mathrm{vmPFC}$ activation in PTSD patients relative to combat controls $(6,60,6 ; Z=4.48,622$ voxels, FWE $p<0.001)$; Figure $3 b$; Table 3), replicating the Milad et al. (2009) results.

\section{Fear renewal}

When the CS+ was re-presented $24 \mathrm{~h}$ after extinction in the acquisition (danger) context, fear renewal was seen, as expected, with greater SCR to CS $+\mathrm{E}$ than $\mathrm{CS}-\left(t_{(23)}=3.69, p=0.001\right)$. A group by stimulus interaction was also significant $\left(F_{(1,22)}=6.69\right.$, $p=0.017$; visible in early fear renewal portion of Fig. 2). Further exploration of this interaction reveals a robust renewal effect in combat control participants, who now had significantly greater SCR to CS+E than to CS $-\left(t_{(11)}=3.66, p=0.004\right)$, whereas for PTSD patients the response differences were substantially smaller and did not reach significance $\left(t_{(11)}=1.925, p=0.08\right)$. To directly compare the combat control and PTSD groups, we quantified ability to differentiate the CS+ from the CS - in renewal by subtracting SCR to CS - from the SCR to CS+E. On this measure of fear expression in the renewal phase, combat control participants showed greater responses than PTSD patients $\left(t_{(15)}=2.60, p=0.02\right)$.

Functional MRI analyses revealed that fear renewal (CS+E relative to CS-) did not elicit significant activations across both groups. When assessed separately, PTSD participants did not display any significant activations to CS + versus CS-; in contrast combat controls activated a number of regions during fear renewal (for CS + versus CS-), including bilateral insula (Table 4). In the interaction analysis (combat controls $>$ PTSD and PTSD > combat controls), these difference for the contrast CS +E versus CS - did not reach statistical significance. To test our a priori hypothesis that PTSD would show unexpectedly low renewal relative to combat control participants, planned comparisons for CS+E and CS - were performed. Combat controls in fact showed greater renewal in SCR (see Fear renewal, above) and also showed greater BOLD signal to CS $+\mathrm{E}$ across a number of brain areas including amygdala, vmPFC, and parietal lobe/ precuneus (Table 4; Fig. 4a,b). In response to the CS-, combat controls had increased activity relative to PTSD patients in the hippocampus, a key area pertaining to memory (Table 4; Fig. 4c). PTSD patients did not display enhanced activation relative to combat controls during renewal, anywhere in the brain, further reinforcing a diminished renewal effect in PTSD.

To insure that these novel findings of neural abnormalities in PTSD during renewal were not due to comorbidity, the analyses were repeated using only the pure PTSD subjects (excluding the 7 with major depressive disorder). The key findings were preserved despite reduced power. Specifically, compared with combat controls, during renewal the PTSD only group manifested reduced signal in the CS + in the amygdala, (right amygdala: $t_{(19)}=-2.5, p=$ 0.025; left amygdala: $\left.t_{(19)}=-2.01, p=0.06\right)$, vmPFC (FWE $p=$ $0.082,250$ voxels, $Z=3.53)$ and right hippocampus $\left(t_{(19)}=-2.17\right.$, $p=0.044)$.

\section{Discussion}

To explore context modulation of memory expression in PTSD and combat controls, subjects were fear conditioned and then extinguished in two different contexts, and then tested for both extinction recall and fear renewal using the safety and danger contexts, respectively. Results indicate that whereas controls used contextual cues to guide fear and extinction memory, the PTSD group showed impaired contextual modulation of both. In combat controls, the safety memory trace prevailed in the safety context, demonstrating intact extinction recall, whereas the fear memory trace prevailed in the danger context. PTSD subjects, in contrast, showed impaired use of contextual cues in both SCR and brain data, failing to appropriately use both safety and danger context information. Specifically, PTSD patients had heightened SCRs to the extinguished CS + versus CS - in the safety context, where contextual cues should have promoted dominance of the extinguished memory trace, suggesting an extinction recall deficit (Milad et al., 2009) because in the extinction context there 
should be no CS +/CS - difference, as seen in combat controls. In contrast, in the danger context, PTSD patients showed little SCR difference between $\mathrm{CS}+\mathrm{E}$ and $\mathrm{CS}-$, where contextual cues should have promoted dominance of the danger signal and a significantly larger relative response to $\mathrm{CS}+\mathrm{E}$, as was seen in controls. PTSD patients in fact showed diminished fear renewal (as measured by SCR CS+E minus CS- difference) when directly compared with controls, which is counter-intuitive given that they generally report feeling endangered everywhere. This reduction in fear expression, however, was predicted by the hypothesis that individuals with PTSD have a general deficit in context processing. In concert with SCR data, $\mathrm{fMRI}$ analyses revealed increased amygdala, insula, and dorsal anterior/midcingulate cortex activation in PTSD patients to the extinguished CS + in the safety context, whereas the combat control group showed increased amygdala and prefrontal activation to the extinguished $\mathrm{CS}+$ in the danger context. PTSD patients thus appeared unable to properly modulate brain activity or conditioned SCRs using contextual information, showing evidence of abnormally high "fear" in a safety context, but abnormally low "fear" in a danger context.

During the conditioning phase, PTSD participants differentiated CS + from CS - as effectively as combat controls (in both SCR and brain activity), showing no abnormal fear generalization to the CS-, as also reported in trauma and anxiety populations (Milad et al., 2009; Jovanovic et al., 2012; Lissek, 2012). PTSD participants also extinguished fear responses to the CS+ effectively, as reflected by loss of SCR differentiation of CS + from CS - after extinction comparable to that seen in combat controls. They also showed reduced brain activations to $\mathrm{CS}+\mathrm{E}$ versus CS - , similar to those in controls. These results add to accumulating evidence of preserved fear and extinction learning in PTSD, consistent with the presence of either a specific extinction recall deficit, or a more general context-processing deficit. Our finding of "low" fear (reflected in SCR and fMRI data) in PTSD participants in the danger context (renewal), however, strongly suggests that they have a more general inability to read or process contextual information properly.

Our data replicate a reported extinction recall deficit in PTSD (Milad et al., 2009), showing heightened return of SCR differentiation of CS + from CS - in the safety context $24 \mathrm{~h}$ after extinction. Brain activations were consistent with this SCR result; PTSD patients showing widespread activity (in CS + E vs CS - contrast) in fear expression regions (e.g., amygdala), as well as memory and somatosensory processing regions (e.g., insula, parietal cortex, anterior/mid-cingulate cortex, and temporal lobe). Insula activation in PTSD patients has been shown to correlate with flashback intensity during trauma script-driven imagery (Osuch et al., 2001). Their enhanced dorsal ACC activation might reflect central representation of enhanced autonomic response (Cersosimo and Benarroch, 2013), or heightened salience detection or attentional capture, as dorsal ACC had been linked to salience network (Ham et al., 2013) and a frontoparietal attention network (Margulies et al., 2007).

As also reported by Milad et al. (2009), extinction recall failure in PTSD was associated with diminished vmPFC signal. Brain activation patterns observed here are consistent with evidence of vmPFC hypoactivity and hippocampal dysfunction in PTSD (Bremner et al., 2003; St Jacques et al., 2011). These may both contribute to a context processing deficit (Liberzon and Sripada, 2007; Maren et al., 2013). Activity in vmPFC was potentially guiding "appropriate" amygdala activation as shaped by context. PTSD patients displayed diminished vmPFC activity relative to controls, and appeared less able to use vmPFC in this fashion. Combat controls on the other hand engaged this vmPFC area in both contexts; perhaps eliciting extinction memory when safety context is identified, and eliciting ("renewing") fear memory when danger context is identified, consistent with recent work suggesting that $\mathrm{mPFC}$ and $\mathrm{mPFC}$-hippocampal interactions are integral in guiding adaptive memory recall based on contextual input (Euston et al., 2012). Combat controls also showed greater hippocampal activity, which may also contribute to their ability to use contextual cues, with PTSD patients perhaps less able to do so. Both structural and functional impairments (for review, see Garfinkel and Liberzon, 2009) in hippocampus have been seen in PTSD, perhaps contributing to vulnerability (Gilbertson et al., 2002). The hippocampus is critical in processing contexts, and may also gate amygdala-based fear both directly and in prefrontal circuits (Sotres-Bayon et al., 2012). Hippocampal involvement and the context processing deficits seen here in PTSD are consistent with this growing body of evidence. Potential breakdown in dual activation of vmPFC and hippocampus may be a key to understanding the neural mechanisms underlying impaired contextual modulation in PTSD.

There are limitations that temper the implications of our findings. Sample size was modest, albeit comparable to previous complex fMRI studies of PTSD (Milad et al., 2009). Replication is needed to confirm positive findings. Lack of significant fMRI findings in interaction analyses recommends caution in conclusions about group differences, but the small sample and lower power also recommend caution in interpreting negative results. In addition to a deficiency in how context informs CS-UCS contingencies, PTSD patients may also have difficulty distinguishing $\mathrm{CS}-$ from $\mathrm{CS}+$, and elevated responses to CS - could contribute to our results, in addition to context problems with CS + . Also, anxiety increases fear generalization, reducing differential CS+/ CS - conditioning (Lissek et al., 2005, 2010), which could contribute to the lack of significant stimulus-by-group interactions in fMRI analyses during fear renewal. PTSD patients also may have increased general reactivity to all stimuli, which could undermine detection of differential effects between stimuli. However, clear differential SCR (to CS+ vs CS-) during fear acquisition, as well as selective fear responding during failed extinction recall, both suggest that PTSD patients were in fact differentiating $\mathrm{CS}+$ and $\mathrm{CS}-$, despite any fear generalization or heightened reactivity. Nevertheless, these could still contribute to lack of significant findings in complex fMRI stimulus-by-group interactions. Future work should be designed and powered to examine differences in brain responses to $\mathrm{CS}-$, and to more definitively identify all regions that are differentially activated between groups and may have contributed to the significant results reported here. This study included only male OEF/OIF veterans, so generalization to women and nonveteran populations requires follow-up studies. Finally, we did not do cognitive testing that could determine whether the general inability to use contextual cues suggested by our data reflects an even more general learning deficit. However, the context-processing problem we observed occurred in the absence of other deficits (in fear learning or extinction). Future work on cognitive function in PTSD might fruitfully focus on other hippocampal and prefrontal cortex dependent cognitive functions that might be associated with a context-processing problem.

Our results suggest that PTSD patients have a deficit in using context to modulate appropriate memory expression, raising the possibility that their extinction recall deficit is a consequence of a more general impairment in using contextual cues. Fear memories that are not modulated by context might contribute to a persistent state of perceived threat and imminent danger, driving 
hyperarousal and avoidant behaviors. Other cues that are not modulated by danger contexts might lead to failure to recognize, avoid, or respond appropriately to novel threats. This idea is particularly intriguing as it might provide a neurobiological explanation for the seemingly counterintuitive clinical evidence that PTSD patients are often exposed to repeated traumas, indicating a potential failure to recognize danger (Deliramich and Gray, 2008; Killgore et al., 2008). These findings thus provide a parsimonious and more comprehensive neurobiological explanation for the inability of PTSD patients to take advantage of safety contexts, as well as potential difficulties identifying and avoiding novel situations that might be dangerous, rooted in both cases in a deficient ability to use contextual information.

\section{References}

Blechert J, Michael T, Vriends N, Margraf J, Wilhelm FH (2007) Fear conditioning in posttraumatic stress disorder: evidence for delayed extinction of autonomic, experiential, and behavioural responses. Behav Res Ther 45:2019-2033. CrossRef Medline

Bouton ME, Westbrook RF, Corcoran KA, Maren S (2006) Contextual and temporal modulation of extinction: behavioral and biological mechanisms. Biol Psychiatry 60:352-360. CrossRef Medline

Bremner JD, Vythilingam M, Vermetten E, Southwick SM, McGlashan T, Nazeer A, Khan S, Vaccarino LV, Soufer R, Garg PK, Ng CK, Staib LH, Duncan JS, Charney DS (2003) MRI and PET study of deficits in hippocampal structure and function in women with childhood sexual abuse and posttraumatic stress disorder. Am J Psychiatry 160:924-932. CrossRef Medline

Brown S, Freeman T, Kimbrell T, Cardwell D, Komoroski R (2003) In vivo proton magnetic resonance spectroscopy of the medial temporal lobes of former prisoners of war with and without posttraumatic stress disorder. J Neuropsychiatry Clin Neurosci 15:367-370. CrossRef Medline

Cersosimo MG, Benarroch EE (2013) Central control of autonomic function and involvement in neurodegenerative disorders. Amsterdam: Elsevier.

De Bellis MD, Keshavan MS, Shifflett H, Iyengar S, Beers SR, Hall J, Moritz G (2002) Brain structures in pediatric maltreatment-related posttraumatic stress disorder: a sociodemographically matched study. Biol Psychiatry 52:1066-1078. CrossRef Medline

Deliramich AN, Gray MJ (2008) Changes in women's sexual behavior following sexual assault. Behav Modif 32:611-621. CrossRef Medline

Euston DR, Gruber AJ, McNaughton BL (2012) The role of medial prefrontal cortex in memory and decision making. Neuron 76:1057-1070. CrossRef Medline

First MB, Spitzer RL, Gibbon M, Williams JBW (2002) Structured clinical interview for DSM-IV-TR axis I disorders, research version, patient edition. New York: Biometrics Research, New York State Psychiatric Institute.

Garfinkel SN, Liberzon I (2009) Neurobiology of PTSD: a review of neuroimaging finding. Psychiatric Ann 39:370-381. CrossRef

Gilbertson MW, Shenton ME, Ciszewski A, Kasai K, Lasko NB, Orr SP, Pitman RK (2002) Smaller hippocampal volume predicts pathologic vulnerability to psychological trauma. Nat Neurosci 5:1242-1247. CrossRef Medline

Ham T, Leff A, de Boissezon X, Joffe A, Sharp DJ (2013) Cognitive control and the salience network: an investigation of error processing and effective connectivity. J Neurosci 33:7091-7098. CrossRef Medline

Jovanovic T, Kazama A, Bachevalier J, Davis M (2012) Impaired safety signal learning may be a biomarker of PTSD. Neuropharmacology 62:695704. CrossRef Medline

Kessler RC, Berglund P, Demler O, Jin R, Merikangas KR, Walters EE (2005) Lifetime prevalence and age-of-onset distributions' of DSM-IV disorders in the national comorbidity survey replication. Arch Gen Psychiatry 62: 593-602. CrossRef Medline

Killgore WD, Cotting DI, Thomas JL, Cox AL, McGurk D, Vo AH, Castro CA, Hoge CW (2008) Post-combat invincibility: violent combat experiences are associated with increased risk-taking propensity following deployment. J Psychiatry Res 42:1112-1121. CrossRef Medline

Liberzon I, Martis B (2006) Neuroimaging studies of emotional responses in PTSD. Ann N Y Acad Sci 1071:87-109. CrossRef Medline
Liberzon I, Sripada CS (2007) The functional neuroanatomy of PTSD: a critical review. Prog Brain Res 167:151-169. CrossRef Medline

Lissek S (2012) The role of conditioned fear generalization in the anxiety disorders: a move toward studying both Pavlovian and instrumental contributions. Psychophysiology 49:S10.

Lissek S, Powers AS, McClure EB, Phelps EA, Woldehawariat G, Grillon C, Pine DS (2005) Classical fear conditioning in the anxiety disorders: a meta-analysis. Behav Res Ther 43:1391-1424. CrossRef Medline

Lissek S, Rabin S, Heller RE, Lukenbaugh D, Geraci M, Pine DS, Grillon C (2010) Overgeneralization of conditioned fear as a pathogenic marker of panic disorder. Am J Psychiatry 167:47-55. CrossRef Medline

Maren S, Phan KL, Liberzon I (2013) The contextual brain: implications for fear conditioning, extinction and psychopathology. Nat Rev Neurosci 14:417-428. CrossRef Medline

Margulies DS, Kelly AM, Uddin LQ, Biswal BB, Castellanos FX, Milham MP (2007) Mapping the functional connectivity of anterior cingulate cortex. Neuroimage 37:579-588. CrossRef Medline

Milad MR, Orr SP, Pitman RK, Rauch SL (2005) Context modulation of memory for fear extinction in humans. Psychophysiology 42:456-464. CrossRef Medline

Milad MR, Wright CI, Orr SP, Pitman RK, Quirk GJ, Rauch SL (2007) Recall of fear extinction in humans activates the ventromedial prefrontal cortex and hippocampus in concert. Biol Psychiatry 62:446-454. CrossRef Medline

Milad MR, Pitman RK, Ellis CB, Gold AL, Shin LM, Lasko NB, Zeidan MA, Handwerger K, Orr SP, Rauch SL (2009) Neurobiological basis of failure to recall extinction memory in posttraumatic stress disorder. Biol Psychiatry 66:1075-1082. CrossRef Medline

Ochsner KN, Bunge SA, Gross JJ, Gabrieli JD (2002) Rethinking feelings: an fMRI study of the cognitive regulation of emotion. J Cogn Neurosci 14: 1215-1229. CrossRef Medline

Orr SP, Metzger LJ, Lasko NB, Macklin ML, Peri T, Pitman RK (2000) De novo conditioning in trauma-exposed individuals with and without posttraumatic stress disorder. J Abnorm Psychol 109:290-298. CrossRef Medline

Orsini CA, Kim JH, Knapska E, Maren S (2011) Hippocampal and prefrontal projections to the basal amygdala mediate contextual regulation of fear after extinction. J Neurosci 31:17269-17277. CrossRef Medline

Osuch EA, Benson B, Geraci M, Podell D, Herscovitch P, McCann UD, Post RM (2001) Regional cerebral blood flow correlated with flashback intensity in patients with posttraumatic stress disorder. Biol Psychiatry 50: 246-253. CrossRef Medline

Pitman RK, Orr SP (1986) Test of the conditioning model of neurosis: differential aversive conditioning of angry and neutral facial expressions in anxiety disorder patients. J Abnorm Psychol 95:208-213. CrossRef Medline

Pole N (2007) The psychophysiology of posttraumatic stress disorder: a meta-analysis. Psychol Bull 133:725-746. CrossRef Medline

Quirk GJ, Russo GK, Barron JL, Lebron K (2000) The role of ventromedial prefrontal cortex in the recovery of extinguished fear. J Neurosci 20:62256231. Medline

Rauch SL, Whalen PJ, Shin LM, McInerney SC, Macklin ML, Lasko NB, Orr SP, Pitman RK (2000) Exaggerated amygdala response to masked facial stimuli in posttraumatic stress disorder: a functional MRI study. Biol Psychiatry 47:769-776. CrossRef Medline

Sotres-Bayon F, Sierra-Mercado D, Pardilla-Delgado E, Quirk GJ (2012) Gating of fear in prelimbic cortex by hippocampal and amygdala inputs. Neuron 76:804-812. CrossRef Medline

Sripada RK, King AP, Garfinkel SN, Wang X, Sripada CS, Welsh RC, Liberzon I (2012a) Altered resting-state amygdala functional connectivity in men with posttraumatic stress disorder. J Psychiatry Neurosci 37:241-249. CrossRef Medline

Sripada RK, King AP, Welsh RC, Garfinkel SN, Wang X, Sripada CS, Liberzon I (2012b) Neural dysregulation in posttraumatic stress disorder: evidence for disrupted equilibrium between salience and default mode brain networks. Psychosom Med 74:904-911. CrossRef Medline

St Jacques PL, Botzung A, Miles A, Rubin DC (2011) Functional neuroimaging of emotionally intense autobiographical memories in posttraumatic stress disorder. J Psychiatry Res 45:630-637. CrossRef Medline 